\title{
Desain dan Simulasi Buck Converter dengan Kontrol Logika Fuzzy Untuk Pengisian Baterai
}

\author{
Azizah Istiqomah Yustikasari ${ }^{1}$, Epyk Sunarno², Putu Agus Mahadi Putra ${ }^{3}$ \\ Program Studi Teknik Elektro Industri, Politeknik Elektronika Negeri Surabaya ${ }^{1}$ \\ Program Studi Teknik Elektro Industri, Politeknik Elektronika Negeri Surabaya ${ }^{2}$ \\ Program Studi Teknik Elektro Industri, Politeknik Elektronika Negeri Surabaya ${ }^{3}$ \\ *azzhistiqomahyst7@gmail.com ${ }^{1}$, epyk@pens.ac.id ${ }^{2}$, mahadi@pens.ac.id ${ }^{3}$
}

\begin{abstract}
Along with the increasing demand for energy, Indonesia has begun to turn to developing alternative energy. Alternative energy that has great potential is solar energy. With the help of solar panels, solar energy will be converted directly into electrical energy. Given that the intensity of sunlight varies, to maximize the conversion process of solar energy, energy is stored in batteries. In the process of storing energy into the battery, the output voltage of the solar panel will vary following the irradiation captured by the solar panel. To adjust the solar panel output voltage, a buck type converter and fuzzy logic control are used to keep the converter output voltage stable. From the results of the system that has been simulated in MATLAB software, the buck converter is able to adjust the solar panel output voltage and fuzzy logic control can run well. The solar panel output voltage for the battery charging process with a capacity of $45 \mathrm{Ah} 12 \mathrm{~V}$ can be stable between $14.4 \mathrm{~V}$ to $14.26 \mathrm{~V}$ from the reference voltage for battery charging of $14.4 \mathrm{~V}$ with irradiation captured by the solar panel between $1000 \mathrm{~W} / \mathrm{m}^{2}$ to $400 \mathrm{~W} / \mathrm{m}^{2}$. By using fuzzy logic control the average error of the buck converter output voltage is $0.37 \%$, it shows that the error obtained is not significant, so fuzzy logic control can be used to control the battery charging voltage so that it is stable.
\end{abstract}

\section{Keywords: Buck Converter, Battery Charging, Fuzzy Logic Control, Solar energy.}

\section{INTISARI}

Seiring dengan meningkatnya kebutuhan energi, Indonesia mulai beralih untuk mengembangkan energi alternatif. Energi alternatif yang mempunyai potensi besar ialah energi surya. Dengan bantuan panel surya, energi surya akan dikonversi secara langsung menjadi energi listrik. Mengingat bahwa intensitas cahaya matahari yang berubah-ubah, untuk memaksimalkan proses konversi energi surya dilakukan penyimpanan energi ke dalam baterai. Dalam proses penyimpanan energi ke baterai, tegangan keluaran panel surya akan berubah-ubah mengikuti iradiasi yang ditangkap oleh panel surya. Untuk mengatur tegangan keluaran panel surya digunakan converter jenis buck dan kontrol logika fuzzy untuk menjaga tegangan keluaran converter agar stabil. Dari hasil sistem yang telah disimulasikan pada software MATLAB, buck converter mampu mengatur tegangan keluaran panel surya dan kontrol logika fuzzy dapat berjalan dengan baik. Tegangan keluaran panel surya untuk proses pengisian baterai dengan kapasitas $45 \mathrm{Ah} 12 \mathrm{~V}$ dapat stabil diantara 14,4 V sampai 14,26 V dari tegangan referensi untuk pengisian baterai sebesar 14,4 V dengan iradiasi yang ditangkap oleh panel surya antara $1000 \mathrm{~W} / \mathrm{m}^{2} \mathrm{sampai} 400 \mathrm{~W} / \mathrm{m}^{2}$. Dengan menggunakan kontrol logika fuzzy rerata error dari tegangan keluaran buck converter sebesar $0,37 \%$, hal tersebut menjukkan bahwa error yang didapat tidak signifikan, sehingga kontrol logika fuzzy dapat digunakan untuk kontrol tegangan pengisian baterai agar stabil.

Kata kunci: Buck Converter, Energi Surya, Kontrol Logika Fuzzy, Pengisian Baterai.

\section{PENDAHULUAN}

Kebutuhan energi akan semakin meningkat setiap tahun, pemakaian energi di Indonesia masih mengandalkan sumber daya energi minyak bumi yang memiliki keterbatasan persediaan [1]. Banyak negara termasuk Indonesia yang mulai beralih untuk mengembangkan energi terbarukan, untuk mendapatkan sumber energi alternatif. Salah satu sumber energi alternatif yang mempunyai potensi besar ialah energi surya, selain ketersediaannya tidak 
akan pernah habis, energi surya juga ramah lingkungan dan dapat diandalkan [2].

Dalam pemanfaatan energi surya digunakan panel surya untuk konversi tenaga surya menjadi tenaga listrik secara langsung. Terlepas dari keuntungan energi surya sebagai energi alternatif, panel surya memiliki kekurangan dalam proses konversi energi surya berkaitan dengan sinar matahari bersifat intermiten, karena dipengaruhi oleh waktu, iklim, polusi, dan musim [3]. Sehingga dilakukan penyimpanan energi ke dalam baterai untuk memaksimalkan proses konversi tenaga surya menjadi tenaga listrik.

Dalam proses penyimpanan energi tersebut, tegangan keluaran dari panel surya tidak stabil [4]. Oleh karena itu, tegangan panel surya akan diatur agar stabil oleh kontrol logika fuzzy dengan topologi buck converter. Buck converter merupakan topologi $D C$ $D C$ Converter dimana nilai dari tegangan keluaran yang dihasilkan bernilai lebih kecil dari tegangan masukan. Kontrol logika fuzzy digunakan untuk mengatur nilai duty cycle pada buck converter, sehingga tegangan keluaran dari buck converter dapat disesuaikan dengan tegangan yang dibutuhkan untuk proses pengisian baterai.

\section{LANDASAN TEORI}

\section{A. Panel Surya}

Panel surya merupakan suatu alat yang dapat mengubah energi matahari menjadi energi listrik. Listrik yang dikeluarkan oleh panel surya dipengaruhi beberapa hal seperti, iradiasi yang ditangkap oleh panel surya, sudut posisi dari modul panel surya, suhu panel surya, dan beda potensial antara panel surya dengan beban (seperti baterai) [5]. Semakin besar iradiasi dan semakin rendah suhunya, semakin besar daya yang dihasilkan oleh panel surya dan sebaliknya. Sementara lebih banyak bayangan yang menutupi panel surya akan membuat daya yang dihasilkan oleh panel surya semakin kecil dan sebaliknya [6].

Spesifikasi dari panel surya yang digunakan pada sistem ini disajikan pada Tabel 1.
Tabel 1. Spesifikasi panel surya

\begin{tabular}{|l|l|}
\hline \multicolumn{1}{|c|}{ Parameter } & \multicolumn{1}{c|}{ Nominal } \\
\hline Model Type & $100 \mathrm{~W}$ \\
\hline Maximum Power (Pmax) & $100 \mathrm{~W} \pm 3 \%$ \\
\hline Voltage at Pmax (Vmax) & $18 \mathrm{~V}$ \\
\hline Current at Pmax (Imax) & $5,56 \mathrm{~A}$ \\
\hline Open Circuit Voltage (Voc) & $22 \mathrm{~V}$ \\
\hline Short Circuit Current (Isc) & $6,06 \mathrm{~A}$ \\
\hline Series Connected & 2 \\
\hline
\end{tabular}

\section{B. Buck Converter}

Buck Converter merupakan jenis non isolated $D C-D C$ converter yang digunakan untuk menurunkan tegangan masukan dengan melakukan pengaturan nilai duty cycle.

Buck converter beroperasi dalam 2 kondisi, yaitu ketika saklar tertutup dan ketika saklar terbuka. Pada saat kondisi saklar tertutup (kondisi $O N$ ), dioda berada dalam kondisi reverse-biased, maka dioda terbias mundur sehingga arus induktor mengalir menuju beban dan menjadikan tegangan induktor bernilai positif. Karena perubahan arus adalah konstan positif, maka arus naik secara linier. Pada saat kondisi saklar terbuka (kondisi $O F F$ ), dioda berada dalam kondisi forward-biased, maka dioda menjadi bias maju yang menyebabkan arus induktor akan mengalir ke sisi beban [3],[7].

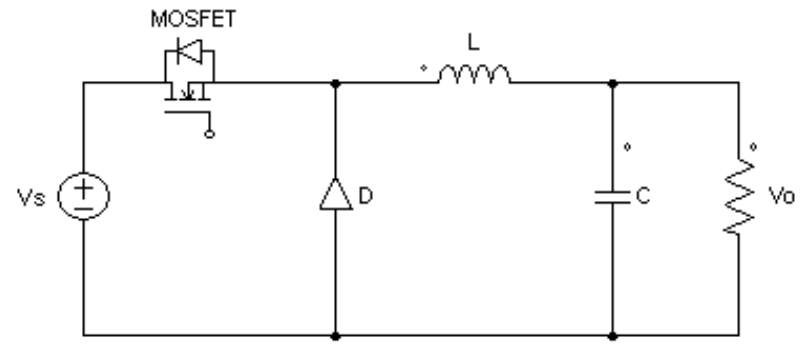

Gambar 1. Rangkaian buck converter

Gambar 1 menunjukkan rangkaian dasar dari buck converter dan persamaan (1) sampai (3) digunakan untuk memodelkan buck converter agar dapat bekerja pada kondisi mode konduksi kontinu (Continuous Conduction Mode/CCM).

$V_{o}=V_{\text {in }} \times D$ 
Jurnal ECOTIPE, Vol. 8, No.2, Oktober 2021, Hal. 59-64

p-ISSN 2355-5068, e-ISSN 2622-4852

Akreditasi Kemenristekdikti (SINTA 4), SK. No.10/E/KPT/2019

DOI: 10.33019/jurnalecotipe.v8i2.2389

$L=\frac{V_{o} \times(1-D)}{\Delta i_{L} \times f}$

$C=\frac{1-D}{8 \times L \times\left(\frac{\Delta V_{O}}{V_{o}}\right) \times f^{2}}$

Keterangan:

$\Delta \mathrm{i}_{\mathrm{L}} \quad=$ Riak arus induktor $(\mathrm{A})$

$\Delta \mathrm{V}_{\mathrm{o}} \quad=$ Riak tegangan kapasitor $(\mathrm{V})$

$\mathrm{C} \quad=$ Nilai kapasitor $(\mathrm{F})$

$\mathrm{D} \quad=$ Duty cycle $(\%)$

$\mathrm{F} \quad=$ Frekuensi switching $(\mathrm{Hz})$

$\mathrm{L} \quad=$ Nilai induktor $(\mathrm{H})$

$V_{o} \quad=$ Tegangan keluaran $(\mathrm{V})$

$V_{\text {in }} \quad=$ Tegangan masukan $(\mathrm{V})$

C. Kontrol Logika Fuzzy

Logika fuzzy diperkenalkan oleh Prof. Lotfi Zadeh pada tahun 1965. Merupakan metode yang mempunyai kemampuan untuk memproses variabel yang bersifat kabur atau tidak dapat dideskripsikan secara pasti seperti tinggi, lambat, bising, dan lainlain. Logika fuzzy memungkinkan nilai keanggotaan antara 0 dan 1 .

Kontrol logika fuzzy berarti kontrol rangkaian tertutup dari proses teknis, termasuk pengolahan nilai yang terukur, berasal dari variabel terukur, dan set poin. Variabel keluaran dalam bentuk variabel pengoreksi. Transformasi harus dilakukan antara masukan dan variabel keluaran dari proses dan dunia fuzzy (fuzzifikasi, defuzzifikasi) komponen inti pengendalian fuzzy terdiri dari linguistik aturan dasar (rule base) dan kesimpulan (inference) [8].

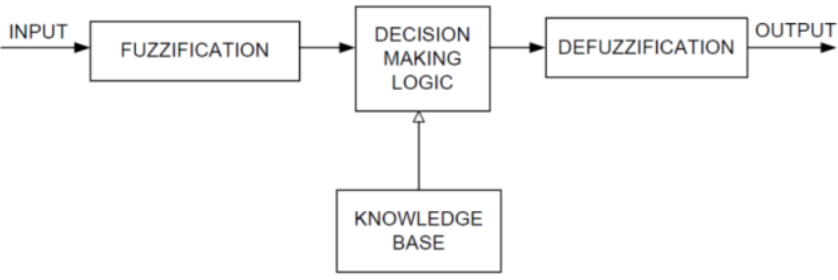

Gambar 2. Blok diagram kontrol logika fuzzy

Kontrol logika fuzzy digolongkan ke dalam kontrol cerdas (intelligent control). Alasan masih digunakannya logika fuzzy sampai sekarang [9], yaitu:

1. Konsep fuzzy logic mudah dimengerti,
2. Fuzzy logic bersifat fleksibel dan memiliki toleransi terhadap data yang kurang tepat,

3. Fuzzy logic mampu membentuk fungsi non linier yang komplek dan didasari pada bahasa alami.

\section{METODE PENELITIAN}

Perencanaan dari sistem yang akan dibuat dapat dilihat melalui blok diagram pada Gambar 3.

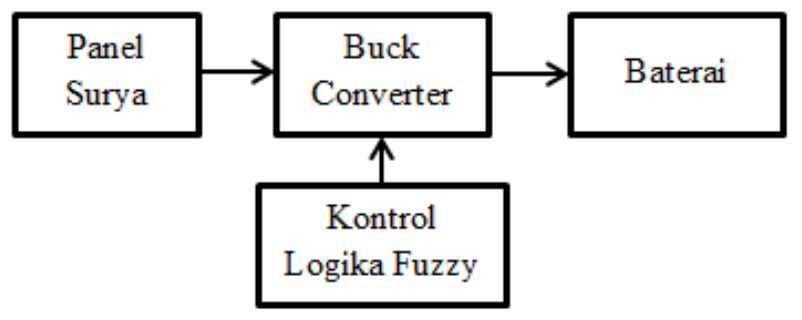

Gambar 3. Blok diagram sistem

Sistem ini dirancang dengan sumber panel surya, dengan tegangan masukan DC sebesar $44 \mathrm{~V}$ yang dihasilkan oleh dua buah panel surya yang disusun secara seri. Tegangan tersebut akan diatur nilainya menjadi 14,4 V melalui buck converter untuk melakukan pengisian baterai dengan kapasitas $45 \mathrm{Ah}$ $12 \mathrm{~V}$. Kontrol logika fuzzy dirancang untuk menjaga tegangan keluaran dari buck converter agar stabil sebagai tegangan pengisian baterai.

\section{A. Perancangan Buck Converter}

Buck converter digunakan untuk mengatur tegangan panel surya agar dapat sesuai nilainya dengan tegangan yang dibutuhkan pada proses pengisian baterai. Dengan bantuan kontrol logika fuzzy tegangan keluaran dari buck converter akan dijaga nilainya agar stabil. Tabel 2 merupakan parameter perancangan buck converter yang digunakan pada sistem.

Tabel 2. Parameter buck converter

\begin{tabular}{|l|l|}
\hline \multicolumn{1}{|c|}{ Parameter } & \multicolumn{1}{c|}{ Nominal } \\
\hline Input Voltage (Vin) & $44 \mathrm{~V}$ \\
\hline Switching Frequency (fs) & $40 \mathrm{kHz}$ \\
\hline Output Voltage (Vout) & $14,4 \mathrm{~V}$ \\
\hline Output Current (Iout) & $4,5 \mathrm{~A}$ \\
\hline Duty Cycle & $33 \%$ \\
\hline Inductor (L) & $268 \mu \mathrm{H}$ \\
\hline Capacitor $(\mathrm{C})$ & $97,656 \mu \mathrm{F}$ \\
\hline
\end{tabular}


Jurnal ECOTIPE, Vol. 8, No.2, Oktober 2021, Hal. 59-64

p-ISSN 2355-5068, e-ISSN 2622-4852

Akreditasi Kemenristekdikti (SINTA 4), SK. No.10/E/KPT/2019

DOI: 10.33019/jurnalecotipe.v8i2.2389

\section{B. Perancangan Kontrol Logika Fuzzy}

Kontrol logika fuzzy berfungsi sebagai sistem kontrol PWM untuk kontrol tegangan (voltage control) keluaran dari buck converter. Kontrol tegangan ini digunakan untuk melakukan pengisian baterai. Fuzzy yang digunakan adalah Fuzzy Type-1, dengan variabel masukan fuzzy yang digunakan ialah nilai tegangan keluaran buck converter yang nantinya akan diolah melalui Fuzzy Inference System dan diubah dalam derajat keanggotaan pada fungsi keanggotaan Error dan Delta Error. Sehingga keluaran fuzzy akan mengatur besarnya duty cycle PWM untuk switching pada rangkaian buck converter.

Error (E) adalah perbedaan nilai antara tegangan referensi dengan tegangan yang terbaca oleh sensor. Sedangkan Delta Error (dE) adalah perbedaan nilai antara error saat ini dengan error sebelumnya. Blok diagram dari kontrol logika fuzzy untuk sistem ini dapat dilihat pada Gambar 4.

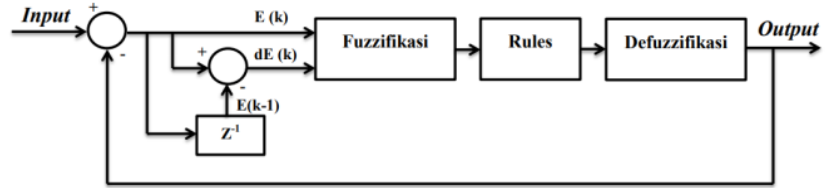

Gambar 4. Blok diagram kontrol logika fuzzy

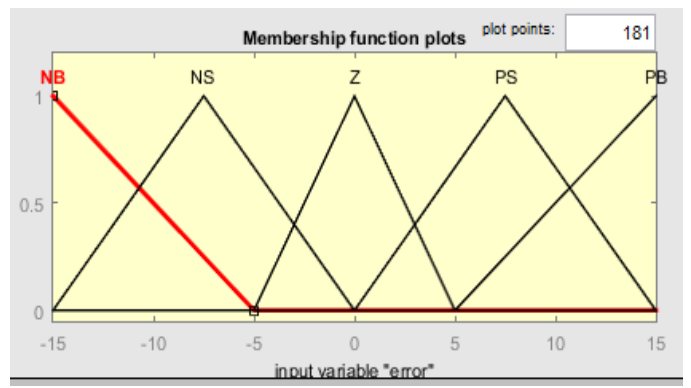

(a)

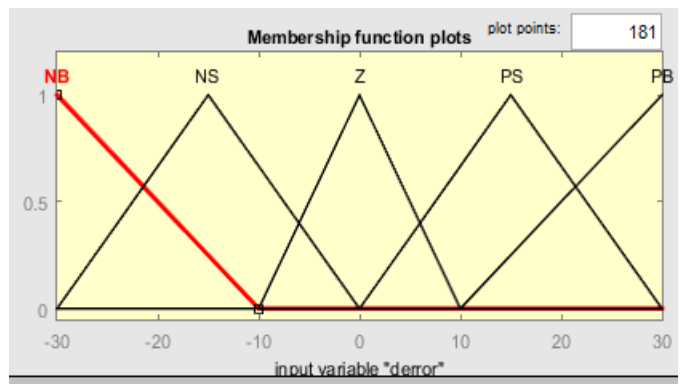

(b)

Gambar 5. Fungsi keanggotaan (a) Error; (b) Delta Error
Dari fungsi keanggotaan yang telah ditentukan, dapat dibentuk rule base yang dapat dilihat seperti pada Tabel 3.

Tabel 3. Perencanaan rule base

\begin{tabular}{|c|c|c|c|c|c|}
\hline $\mathbf{E} / \mathbf{d E}$ & $\mathbf{N B}$ & $\mathbf{N S}$ & $\mathbf{Z}$ & $\mathbf{P S}$ & $\mathbf{P B}$ \\
\hline NB & NB & NB & NB & NS & Z \\
\hline NS & NB & NB & NS & Z & PS \\
\hline $\mathbf{Z}$ & NB & NS & Z & PS & PB \\
\hline PS & NS & Z & PS & PB & PB \\
\hline PB & Z & PS & PB & PB & PB \\
\hline
\end{tabular}

Keterangan:

$\begin{array}{ll}\mathrm{NB} & =\text { Negative Big } \\ \mathrm{NS} & =\text { Negative Small } \\ \mathrm{Z} & =\text { Zero } \\ \mathrm{PS} & =\text { Positive Small } \\ \mathrm{PB} & =\text { Positive Big }\end{array}$

\section{HASIL PENELITIAN DAN PEMBAHASAN}

\section{A. Simulasi Open Loop}

Simulasi dilakukan menggunakan software MATLAB. Dengan menghubungkan panel surya sebagai sumber masukan dari buck converter, tegangan keluaran dari buck converter akan digunakan sebagai tegangan pengisian baterai. Pada sistem open loop (rangkaian terbuka) seperti yang ditunjukkan Gambar 6 simulasi dilakukan dengan mengubah nilai duty cycle secara manual untuk mendapatkan tegangan keluaran dari buck converter sebesar 14,4 V. Data hasil simulasi open loop ditunjukkan pada Tabel 4 , perubahan iradiasi panel surya sebagai acuan dalam pengambilan data.

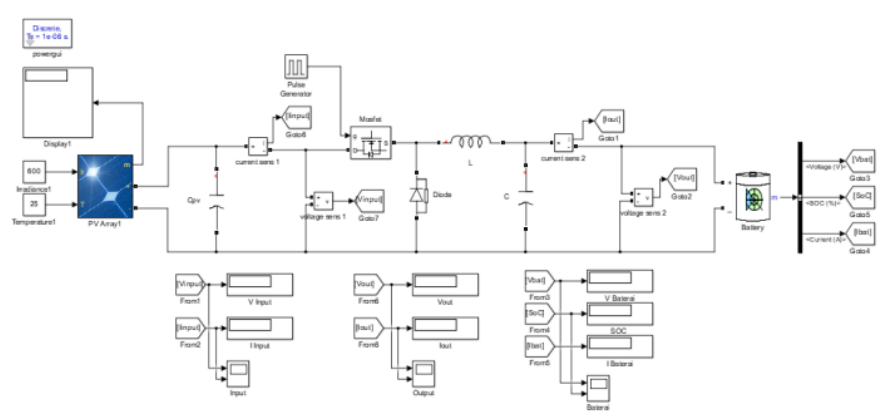

Gambar 6. Rangkaian simulasi open loop 
Jurnal ECOTIPE, Vol. 8, No.2, Oktober 2021, Hal. 59-64

p-ISSN 2355-5068, e-ISSN 2622-4852

Akreditasi Kemenristekdikti (SINTA 4), SK. No.10/E/KPT/2019

DOI: 10.33019/jurnalecotipe.v8i2.2389

Tabel 4. Data simulasi pengisian baterai open loop

\begin{tabular}{|c|c|c|c|c|c|c|c|}
\hline $\begin{array}{c}\text { Iradiasi } \\
\left(\mathrm{W} / \mathrm{m}^{2}\right)\end{array}$ & $\begin{array}{c}\text { Vin } \\
(\mathrm{V})\end{array}$ & $\begin{array}{c}\text { Set } \\
\text { Point } \\
(\mathrm{V})\end{array}$ & $\begin{array}{c}\text { Vout } \\
(\mathrm{V})\end{array}$ & $\begin{array}{c}\text { Iin } \\
(\mathrm{A})\end{array}$ & $\begin{array}{c}\text { Iout } \\
(\mathrm{A})\end{array}$ & $\begin{array}{c}\text { Duty } \\
\text { Cycle }\end{array}$ & $\begin{array}{c}\text { Error } \\
(\%)\end{array}$ \\
\hline 1000 & 42,29 & 14,4 & 14,77 & 1,10 & 5,07 & $33 \%$ & 2,57 \\
\hline 800 & 41,97 & 14,4 & 14,58 & 1,03 & 4,73 & $35 \%$ & 1,25 \\
\hline 600 & 41,27 & 14,4 & 14,34 & 1,11 & 4,27 & $36 \%$ & 0,42 \\
\hline 400 & 37,91 & 14,4 & 14,68 & 1,05 & 4,90 & $37 \%$ & 1,94 \\
\hline \multicolumn{8}{|c|}{ atata Error } \\
\hline
\end{tabular}

Dari data simulasi pada Tabel 4 dapat diketahui bahwa tegangan keluaran buck converter untuk pengisian baterai sebesar $14,77 \mathrm{~V}$ sampai $14,68 \mathrm{~V}$. Nilai tersebut melebihi tegangan referensi (set point) dan tidak stabil. Rerata error yang dihasilkan dari simulasi open loop ialah sebesar $1,55 \%$.

\section{B. Simulasi Close Loop}

Simulasi close loop sistem pada proses pengisian baterai dilakukan dengan menambahkan kontrol logika fuzzy untuk menjaga tegangan keluaran dari buck converter agar stabil, dapat dilihat pada Gambar 7. Dari hasil simulasi yang telah dilakukan dengan menambahkan kontrol logika fuzzy pada sistem mampu menjaga tegangan keluaran dari buck converter $\pm 14,4 \mathrm{~V}$ dengan persentasi rerata error lebih kecil dari sistem tanpa kontrol (open loop) sebesar 0,37\%. Data simulasi close loop ditunjukkan pada Tabel 5. Grafik perbandingan tegangan keluaran buck converter tanpa kontrol dan menggunakan kontrol fuzzy disajikan pada Gambar 10, menunjukkan bahwa tegangan keluaran menggunakan kontrol logika fuzzy lebih stabil dan mendekati tegangan referensi yang telah ditentukan.

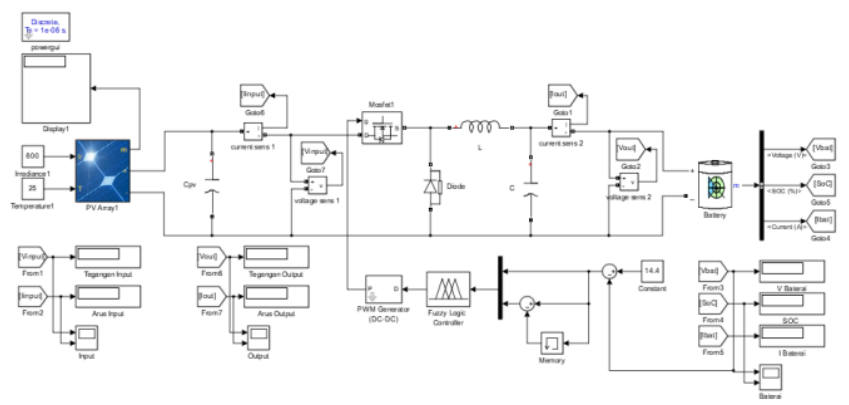

Gambar 7. Rangkaian simulasi close loop
Tabel 5. Data simulasi pengisian baterai close loop

\begin{tabular}{|c|c|c|c|c|c|c|}
\hline $\begin{array}{c}\text { Iradiasi } \\
\left(\mathrm{W} / \mathrm{m}^{2}\right)\end{array}$ & $\begin{array}{c}\text { Vin } \\
(\mathrm{V})\end{array}$ & $\begin{array}{c}\text { Iin } \\
(\mathrm{A})\end{array}$ & $\begin{array}{c}\text { Set } \\
\text { Point } \\
(\mathrm{V})\end{array}$ & $\begin{array}{c}\text { Vout } \\
(\mathrm{V})\end{array}$ & $\begin{array}{c}\text { Iout } \\
(\mathrm{A})\end{array}$ & $\begin{array}{c}\text { Error } \\
(\%)\end{array}$ \\
\hline 1000 & 42,76 & 1,18 & 14,4 & 14,41 & 4,392 & 0,03 \\
\hline 800 & 42,14 & 1,04 & 14,4 & 14,39 & 4,371 & 0,07 \\
\hline 600 & 41,28 & 1,129 & 14,4 & 14,34 & 4,267 & 0,42 \\
\hline 400 & 40,92 & 1,714 & 14,4 & 14,26 & 2,454 & 0,97 \\
\hline \multicolumn{6}{|c|}{ atata Error } & 0,37 \\
\hline
\end{tabular}

Gambar 8. Tegangan pengisian pada baterai saat close loop

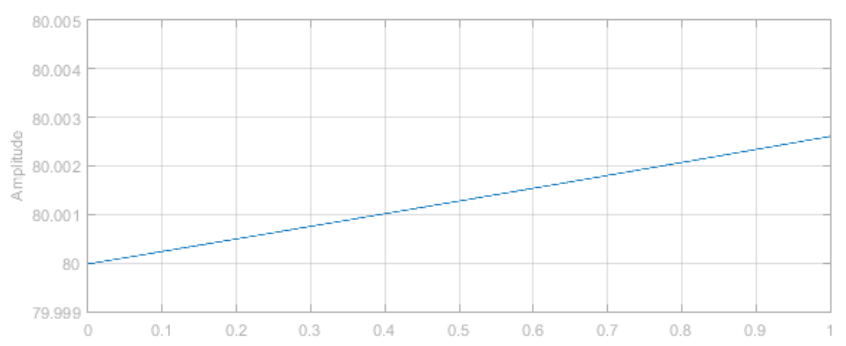

Gambar 9. SOC pada baterai

Gambar 8 menunjukkan bentuk gelombang dari tegangan pengisian baterai dengan menggunakan kontrol logika fuzzy. Kemudian, pada Gambar 9 ialah proses pengisian baterai dengan SOC baterai sebesar $80 \%$, terjadi proses kenaikan gelombang dari SOC awal sebesar $80 \%$ menjadi $80,0025 \%$ selama 1 detik yang menunjukkan bahwa terjadi proses pengisian daya pada baterai. 
Jurnal ECOTIPE, Vol. 8, No.2, Oktober 2021, Hal. 59-64

p-ISSN 2355-5068, e-ISSN 2622-4852

Akreditasi Kemenristekdikti (SINTA 4), SK. No.10/E/KPT/2019

DOI: 10.33019/jurnalecotipe.v8i2.2389

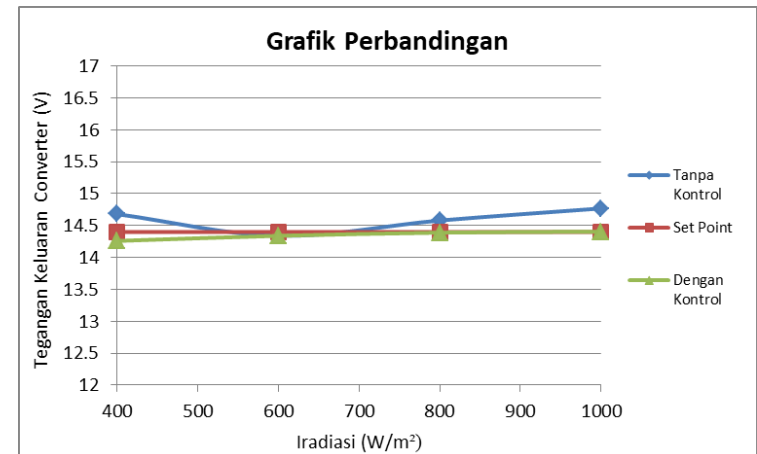

Gambar 10. Grafik perbandingan tegangan keluaran buck converter tanpa kontrol dan dengan kontrol fuzzy

\section{KESIMPULAN}

Setelah dilakukan proses simulasi menggunakan MATLAB dengan membandingkan dua kondisi, yaitu open loop (tanpa kontrol fuzzy) dan close loop (dengan kontrol fuzzy), buck converter yang dirancang mampu menurunkan nilai tegangan dari sumber panel surya untuk melalukan pengisian baterai. Buck converter dengan kontrol logika fuzzy dapat memberikan tegangan keluaran yang stabil untuk proses pengisian baterai ketika nilai iradiasi berubah-ubah. Kontrol logika fuzzy pada sistem mampu menekan nilai error dari tegangan keluaran converter dari $1,55 \%$ menjadi $0,37 \%$.

\section{REFERENSI}

[1] Imam Kholiq, "Pemanfaatan Energi Alternatif Sebagai Energi Terbarukan Untuk Mendukung Substitusi BBM", Jurnal IPTEK Vol. 19 No. 2, Desember 2015, hal. 75-91.

[2] L. P. S. Raharja, R. P. Eviningsih, I. Ferdiansyah, D. S. Yanaratri, "Penggunaan Daya Panel Surya Dengan MPPT Bisection Pada Proses Charging Baterai", Jurnal Teknologi Terpadu Vol. 9 No.1, April 2021, hal. 24-33.

[3] A. S. Pratiwi, S. D. Nugraha, E. Sunarno, "Desain dan Simulasi Bidirectional DC-DC Converter Untuk Penyimpann Energi Pada Sistem Fotovoltaik", Jurnal Nasional Teknik Elektro dan Teknologi Informasi Vol. 9 No. 3, Agustus 2020, hal. 305-310.
[4] A. Maulidiyah, A. P. Parastiwi, D. Dewatama, "Perancangan dan Realisasi Buck \& Boost Converter Menggunakan Algoritma Maximum Power Point Tracker dengan Kontrol Fuzzy Logic pada Pembangkit Listrik Tenaga Surya", Jurnal Elkolind, Mei 2017, Vol.04, No. 1, hal. 30-36.

[5] H. N. Shoumi, I. Sudiharto, E. Sunarno, "Design of the CUK Converter with PI Controller for Battery Charging", 2020 International Seminar on Application for Technology of Information and Communication (iSemantic). IEEE, 2020.

[6] A. R. Nansur, A. S. L. Hermawan, F. D. Murdianto, "Constant voltage control using fuzzy logic controller (FLC) to overcome the unstable output voltage of MPPT in DC microgrid system", 2018 International Electronics Symposium on Engineering Technology and Applications (IES-ETA). IEEE, 2018.

[7] S. T. Aprilyani, I. Irianto, dan E. Sunarno, "Desain dan Komparasi Kontrol Kecepatan Motor DC", Jurnal Ecotipe (Electronic, Control, Telecommunication, Information, and Power Engineering) Vol. 7 No. 2, hal. 127-134.

[8] D. Dewatama, M. Fauziyah, dan H. K. Safitri, "Optimasi Buck Converter Pada Tree Menggunakan Kontrol Logika Fuzzy", JURNAL ELTEK Vol.15 No.2, hal. 36-51.

[9] Sri Kusumadewi dan Hari Purnomo, "Aplikasi Logika Fuzzy untuk Pendukung Keputusan", 2010.

[10] D.W. Hart, "Power Electronics", New York, USA: McGraw-Hill, 2010.

[11] Timothy J. Ross, "Fuzzy Logic With Engineering Application", John Wiley \& Sons , Ltd.University of New Mexico.Third Edition. 